\title{
Sparfloxacin Distribution in Human Saliva
}

\author{
Mikaela Kolaci ${ }^{1 *}$, and Leonard Deda² \\ ${ }^{1}$ National Agency of Medicines and Medical Devices, Tirana, Albania \\ ${ }^{2}$ Department of Pharmacology, Faculty of Medicine, Tirana, Albania
}

*Corresponding author: Mikaela Kolaci, National Agency of Medicines and Medical Devices, Tirana, Albania, Tel: 0695303079; E-mail: mikaela_kolaci@yahoo.com

Received: 23 Nov, 2020 | Accepted: 21 Dec, 2020 | Published: 29 Dec, 2020

Citation: Kolaci M, Deda L (2020) Sparfloxacin Distribution in Human Saliva. J Drug Res Dev 6(2): dx.doi.org/10.16966/2470-1009.157

Copyright: (C) 2020 Kolaci M, et al. This is an open-access article distributed under the terms of the Creative Commons Attribution License, which permits unrestricted use, distribution, and reproduction in any medium, provided the original author and source are credited.

\section{Abstract}

Aim: The aim of this study is to assess the penetration of sparfloxacin in mixed human saliva after a single oral dose of $400 \mathrm{mg}$ in Caucasian healthy subjects.

Background: Fluoroquinolones are a group of relatively new antibiotics with a broad and effective spectrum of antimicrobial activity. Fluoroquinolones have been reported to distribute well into saliva. Data on the distribution of sparfloxacin in human saliva are very scarce and limited to Japanese subjects.

Method: Six healthy volunteers participated in the study. Blood and saliva samples were taken prior to sparfloxacin administration and thereafter at $2,4,6,8,10,28,54$ hours after dosing. The concentrations of sparfloxacin in plasma and saliva were determined by a validated HPLC method, for each biological matrix. The maximal concentration $\left(C_{\max }\right)$ and time to reach $C_{\max }\left(T_{\max }\right)$ of sparfloxacin in plasma and saliva were determined by direct observation of the data. The AUC, for both plasma and saliva, were calculated using trapezoidal rule.

The mean penetration of the drug into saliva was calculated by the ratio $A \cup C_{0-\infty}$ saliva / $A \cup C_{0-\infty}$ plasma and also by the average of Saliva/Plasma ratio for each concentration during the elimination phase.

Results: The mean $\mathrm{C}_{\max }$ of sparfloxacin in plasma was $1.98 \mu \mathrm{g} / \mathrm{mL}$ with a mean $\mathrm{T}_{\max }$ of $4.3 \mathrm{~h}$ after oral administration. Mean terminal elimination half-life $\left(t_{1 / 2 \beta}\right)$ from plasma was $18.4 \mathrm{~h}$ (range 13.4-23.2 h). The $A U C_{0-54}$ and $A U C_{0-\infty}$ were $46.9 \mu g_{*} \mathrm{~h} / \mathrm{mL}$ and $53.6 \mu g_{*} \mathrm{~h} / \mathrm{mL}$, respectively. Penetration of sparfloxacin in saliva was good and rapid. Two peak saliva concentrations were observed in 5 subjects, the first one appearing at $2 \mathrm{~h}$ after dosing, before the plasma Cmax was reached. Post-absorption phase mean $\mathrm{C}_{\max }$ in saliva was $1.8 \mu \mathrm{g} / \mathrm{mL}$ with a $\mathrm{T}_{\max }$ of $5.3 \mathrm{~h}$ after oral administration. Mean terminal elimination half-life $\left(\mathrm{t}_{1 / 2}\right)$ from saliva was $15.8 \mathrm{~h}$ (range 13.9-18.2 $\mathrm{h}$ ).

Conclusions: Following the administration of an oral dose of $400 \mathrm{mg}$ sparfloxacin in healthy Caucasian adults saliva concentrations were 62.8 to $71.3 \%$ of the corresponding plasma concentrations with an overall penetration of sparfloxacin into saliva of $68.4 \%$.

Keywords: Sparfloxacin; Human saliva; Distribution; Pharmacokinetic parameters

\section{Introduction}

Fluoroquinolones are a group of relatively new antibiotics with a broad and effective spectrum of antimicrobial activity against both gram-negative and gram-positive bacteria.

Sparfloxacin was approved for medical use in 1993. The main potential advantages of sparfloxacin over older fluoroquinolones are its improved activity against Gram-positive pathogens and its long half-life that allows once-daily dosing [1].

Sparfloxacin is readily absorbed and has oral bioavailability of 92\% and half-life of 16-20 hours [2-4]. Peak serum concentrations are reached 3-5 hours following oral administration. Sparfloxacin binds weakly to plasma protein (37\%), and exhibits excellent tissue distribution and effective penetration into extracellular fluids. Concentrations of the drug in most tissues are similar to, or higher than, concomitant plasma concentrations [5]. Studies performed in animals and humans have demonstrated that fluoroquinolones, such as ciprofloxacin, norfloxacin, ofloxacin, pefloxacin and moxifloxacin distribute well into human saliva. Recently, a systematic review and a qualitative review of the literature on the pharmacokinetics of antibiotics in saliva have been published [6,7]. However, data on sparfloxacin distribution in human saliva are very limited.

The aim of this study was to assess the penetration of sparfloxacin in mixed human saliva after a single oral dose of $400 \mathrm{mg}$ in healthy Caucasian subjects. 


\section{Materials and Methods}

\section{Ethics}

The study protocol was reviewed and approved by the National Ethics Committee. The study was conducted in accordance with the requirements of the GCP and the principles of the Helsinki Declaration. Informed written consent was obtained from all subjects.

\section{Study design}

This was a prospective, open-label, paired-sample controls study. A single dose of sparfloxacin 400mg (SPARFLO 200mg tablets, Dr. Reddy's) was administered orally with $200 \mathrm{ml}$ of water to each overnight fasted subject. There was no restriction on fluid intake. Food was allowed 4 hours after the administration.

\section{Volunteers}

Sixhealthyvolunteers participated in the study. Physical examination, electrocardiograms, and laboratory screening (hematological and biochemical parameters) were all normal before and after the study. Exclusion criteria were acute or chronic diseases, blood donation 8 weeks prior to study, known or suspected hypersensitivity to the quinolones, alcohol consumption, pregnancy, or intention to become pregnant. The use of any additional medication 2 weeks prior to or during the study period was not allowed.

\section{Sample collection and processing}

Blood samples $(5 \mathrm{~mL})$ were taken from a peripheral vein, through an indwelling catheter, prior to sparfloxacin administration and then at $2,4,6,8,10,28,54$ hours after dosing. Blood specimens were collected in heparinized tubes and were subsequently centrifuged at $3500 \mathrm{rpm}$ for 10 minutes. A $100 \mu \mathrm{L}$ of perchloric acid $12 \%$ was added to a $100 \mu \mathrm{L}$ aliquot of plasma to precipitate the proteins. The mixture was vortexed for $30 \mathrm{sec}$. and centrifuged for $5 \mathrm{~min}$ at $5000 \mathrm{rpm}$. The supernatant was injected manually.

Whole mixed saliva was collected at the same intervals, after previous rinse of the oral cavity with $50 \mathrm{~mL}$ of water, which was discharged. Saliva production was stimulated by chewing of a parafilm and collected $(2 \mathrm{ml})$ by spitting into a tube, which was centrifuged at $9000 \mathrm{rpm}$ for 10 minutes to remove mucus or particulate matter. Saliva was filtered and injected without further preparation.

Plasma, saliva and standard solutions were stored at $-4^{\circ} \mathrm{C}$ until analysis.

\section{Drug analysis}

The concentrations of sparfloxacin in plasma and saliva were determined by HPLC, using a validated method for each biological matrix. A reversed-phase LiChrospher RP18, $5 \mu \mathrm{m}$ column $(250 \mathrm{~mm}$ $\times 3 \mathrm{~mm}$ i.d: Hewlett Packard), a binary pump (Hewlett Packard 1100 ) and a manual injector (Rheodyne), $20 \mu \mathrm{L}$ loop, were used. UV detection was made at $300 \mathrm{~nm}$, for both plasma and saliva, using a UVVIS detector (Hewlett Packard 1100) was pumped isocratically.

The lower limit of quantification for plasma and saliva were $0.125 \mu \mathrm{g} / \mathrm{mL}$ and $0.05 \mu \mathrm{g} / \mathrm{mL}$, respectively. The intra-run and betweenrun coefficients of variation were less than $12.6 \%$ for plasma and less than $8.7 \%$ for saliva.

Mobile phase, a mixture of acetonitrile $25 \%$ and $0.05 \mathrm{M} \mathrm{KH}_{2} \mathrm{PO}_{4}$, to which $5 \%$ dimethylformamide was added.

\section{Pharmacokinetic analysis}

The maximum concentration $\left(\mathrm{C}_{\max }\right)$ of sparfloxacin in plasma or saliva and time to reach $\mathrm{C}_{\max }\left(\mathrm{T}_{\max }\right)$ were determined by direct observation of the data. $\mathrm{AUC}_{0-54}$ for both plasma and saliva, were calculated using trapezoidal rule. $\mathrm{AUC}_{54-\infty}$ was calculated by the ratio of last measured concentration and the terminal elimination rate constant $\left(\mathrm{K}_{\mathrm{el}}\right)$. $\mathrm{K}_{\mathrm{el}}$ was estimated by linear regression of the linear portion of the $\log$ transformed concentration versus time. The terminal elimination half-life $\left(t_{1 / 2}\right)$ was calculated by the formula: $t_{1 / 2}=\ln (2) / K_{e l}$.

The mean penetration of the drug into saliva was calculated by the ratio $\mathrm{AUC}_{0-\infty}$ saliva / $\mathrm{AUC}_{0-\infty}$ plasma and also by the average of Saliva/ Plasma ratio for each concentration during the elimination phase.

\section{Statistical analysis}

Results are shown as arithmetic means \pm SE. In case of comparisons the appropriate parametric or nonparametric test was chosen after testing the respective data for normal distribution. Statistical significance was defined as a $P$ value of $<0.05$.

\section{Results}

All six volunteers (three males and three females), mean age $34 \pm$ 3.2 years, completed the study. Sparfloxacin was well tolerated. No physical, biochemical or hematological abnormalities related to the administration of sparfloxacin were observed.

The mean concentration-time curves for plasma and saliva, after the administration of a single oral dose of sparfloxacin $400 \mathrm{mg}$, are shown in the figure 1. Pharmacokinetic parameters are summarized in the table 1 .

The mean $\mathrm{C}_{\max }$ in plasma was $1.98 \mu \mathrm{g} / \mathrm{mL}$ with a $\mathrm{T}_{\max }$ of $4.3 \mathrm{~h}$ after oral administration. $\mathrm{AUC}_{0-54}$ and $\mathrm{AUC}_{0-\infty}$ were $46.9 \mu \mathrm{g}^{\star} \mathrm{h} / \mathrm{mL}$ and $53.6 \mu \mathrm{g}^{\star} \mathrm{h} / \mathrm{mL}$, respectively. The mean value of terminal elimination half-life $\left(\mathrm{t}_{1 / 2 \beta}\right)$ from plasma was $18.4 \mathrm{~h}$ (range 13.4-23.2 h).

Penetration of sparfloxacin in saliva was good and rapid. Two peak concentrations of sparfloxacin in saliva were observed in 5 subjects, the first one appearing at $2 \mathrm{~h}$ after dosing and before the maximal plasma concentrations were reached. Post-absorption phase mean $\mathrm{C}_{\max }$ in saliva was $1.8 \mu \mathrm{g} / \mathrm{ml}$ with mean $\mathrm{T}_{\max }$ attained $5.3 \mathrm{~h}$ after oral administration. AUC $_{0-54}$ and $\mathrm{AUC}_{0-\infty}$ were $33.6 \mu \mathrm{g}^{\star} \mathrm{h} / \mathrm{ml}$ and $36.7 \mu \mathrm{g}^{\star} \mathrm{h} /$ $\mathrm{ml}$, respectively. The mean value of terminal elimination half-life $\left(\mathrm{t}_{1 / 2 \beta}\right)$ from saliva was $15.8 \mathrm{~h}$ (range 13.9-18.2 h).

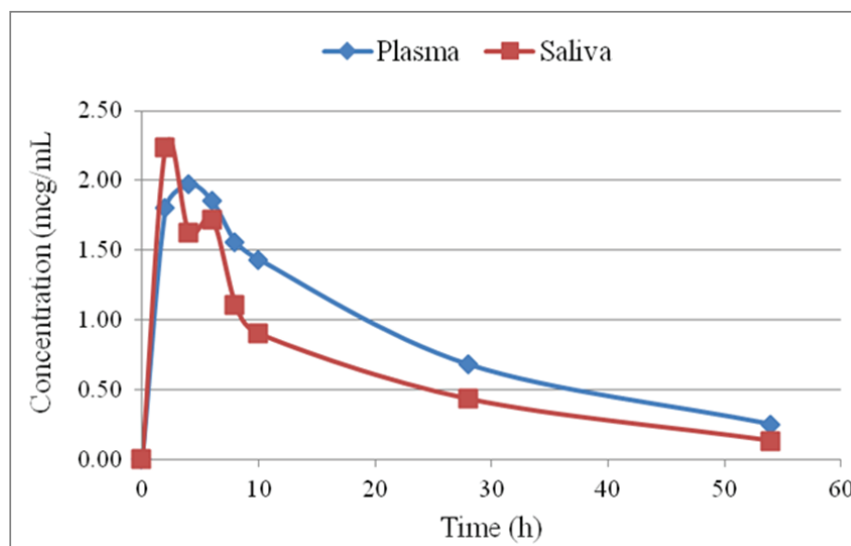

Figure 1: Sparfloxacin mean concentration in plasma over $54 \mathrm{~h}$.

The mean penetration percentage into saliva, calculated as $\mathrm{AUC}_{0}$ $\left.{ }_{\infty}(\mathrm{S}) / \mathrm{AUC}_{0-\infty} \mathrm{P}\right)$ and $\mathrm{AUC}_{0-54}(\mathrm{~S}) / \mathrm{AUC}_{0-54}(\mathrm{P})$ were $68.4 \%$ and $71.6 \%$, respectively. The ratios of saliva/plasma concentrations at 8,10 and 28 hours post dose were $71.3 \%, 62.8 \%$ and $63.6 \%$, respectively. 
Table 1: Sparfloxacin plasma and saliva pharmacokinetic parameters.

\begin{tabular}{|l|c|c|c|c|}
\hline \multirow{2}{*}{} & \multicolumn{2}{|c|}{ Plasma } & \multicolumn{2}{c|}{ Saliva } \\
\cline { 2 - 5 } & Mean \pm SE & CV & Mean \pm SE & CV \\
\hline \multirow{2}{*}{$C_{\text {max }}(\mathrm{mcg} / \mathrm{mL})$} & $2.07 \pm 0.31$ & \multirow{2}{*}{$36.4 \%$} & $2.3 \pm 0.52$ & 54.8 \\
\hline \multirow{2}{*}{$\mathrm{T}_{\text {max }}(\mathrm{h})$} & $4.33 \pm 0.33$ & 18.8 & $3.8 \pm 0.31 *$ & 43.3 \\
\hline $\mathrm{t}_{1 / 2 \beta}(\mathrm{h})$ & $18.4 \pm 1.34$ & 17.9 & $15.8 \pm 0.84$ & 62 \\
\hline $\mathrm{AUC}_{0-54}\left(\mu \mathrm{g}^{*} \mathrm{~h} / \mathrm{mL}\right)$ & $46.9 \pm 6.85$ & 35.7 & $33.6 \pm 3.61$ & 30.6 \\
\hline $\mathrm{AUC}_{0-\infty}\left(\mu \mathrm{g}^{*} \mathrm{~h} / \mathrm{mL}\right)$ & $53.6 \pm 6.99$ & 31.9 & $36.7 \pm 4.08$ & 26.8 \\
\hline
\end{tabular}

*post-absorption phase

$\mathrm{CV}$ coefficient of variation

\section{Discussion}

Sparfloxacin pharmacokinetics, as well as its tissue and body fluids penetration have been reported in several studies. In Caucasian volunteers and patients plasma sparfloxacin concentrations reached a peak of $1.2-1.5 \mathrm{mg} / \mathrm{L}$ between 3 and $6 \mathrm{~h}$ after a single $400 \mathrm{mg}$ dose; $\mathrm{t}_{1 / 2}$ ranged from 16 to $22 \mathrm{~h}$ [3]. Zhanel GG, et al. [8] for an oral dose of $40 \mathrm{mg}$ has reported a $\mathrm{C}_{\max }$ value of $1.30 \mathrm{mcg} / \mathrm{ml}$ and a $\mathrm{T}_{\max }$ of 4.5 hours. In an open, randomized, triple crossover study, the effects of cisapride and sucralfate on the pharmacokinetics of sparfloxacin were assessed. Fifteen healthy volunteers received $400 \mathrm{mg}$ of sparfloxacin as a single oral dose. Pharmacokinetic parameters for sparfloxacin alone were as follows (mean \pm standard deviation): maximum concentration of drug in serum $\left(\mathrm{C}_{\max }\right), 1.27 \pm 0.39 \mathrm{mcg} / \mathrm{ml}$; time to $\mathrm{C}_{\max }\left(\mathrm{T}_{\max }\right), 4.1 \pm 1.9$ $\mathrm{h}$; area under the concentration-time curve (AUC), $35.0 \pm 9.7 \mu \mathrm{g}^{\star} \mathrm{h} /$ $\mathrm{ml}$ [9]. In another study, a single $400 \mathrm{mg}$ oral dose of sparfloxacin was given to each of six healthy male volunteers, and the concentrations of the drug were measured in plasma. The mean peak concentration in plasma of 1.6 micrograms $/ \mathrm{ml}$ was attained at a mean time of $2.7 \mathrm{~h}$ post dose. The mean elimination half-life in plasma was $17.6 \mathrm{~h}$ [10]. In our study $\mathrm{C}_{\max }$ and $\mathrm{AUC}_{0-\infty}$ were found to be slightly higher, while $\mathrm{T}_{\max }$ was similar with the results of other studies. Was also higher than those of other studies.

To our knowledge, this is the first study which evaluates saliva penetration of sparfloxacin $400 \mathrm{mg}$, given orally, in healthy Caucasian adults. We were unable to identify any data on salivary distribution of sparfloxacin in humans, apart those reported by Shimada J, et al [5]. In their work they make reference to a study of Naitoh done in 10 Japanese males, with a single oral dose of $200 \mathrm{mg}$ sparfloxacin, where they found saliva and plasma $\mathrm{C}_{\max }$ to be respectively $0.97 \mathrm{mcg} / \mathrm{ml}$ and $1.38 \mathrm{mcg} / \mathrm{ml}$, with a ratio of $70 \%$, and to a study of Nakashima done in 6 Japanese males, also with a single oral dose of $200 \mathrm{mg}$ sparfloxacin, where saliva and plasma $\mathrm{C}_{\max }$ respectively $0.43 \mathrm{mcg} / \mathrm{mL}$ and $0.65 \mathrm{mcg} /$ $\mathrm{ml}$, with a ratio of $66 \%$, were found.

In our study, higher saliva concentrations than respective plasma concentrations was observed during the absorption phase. In general, saliva concentration of fluoroquinolones during absorption phase are lower than corresponding plasma concentrations, but this may not be true for moxifloxacin. Stass $\mathrm{H}$, et al. [11] reported moxifloxacin salivary concentrations to be higher than respective plasma concentrations during the absorption phase.

\section{Conclusions}

In conclusion, following the administration of an oral dose of $400 \mathrm{mg}$ sparfloxacin in healthy Caucasian adults saliva concentrations were 62.8 to $71.3 \%$ of the corresponding plasma concentrations with an overall penetration of sparfloxacin into saliva of $68.4 \%$.

\section{References}

1. Richard P, Gutmann L (1992) Sparfloxacin and other new fluoroquinolones. J Antimicrob Chemother 30: 739-744.

2. Montay G, Bruno R, Vergniol JC, Ebmeier M, Le Roux Y, et al. (1994) Pharmacokinetics of sparfloxacin in humans after single oral administration at doses of 200,400,600 and 800mg. J Clin Pharmacol 34: 1071-1076.

3. Montay G (1996) Pharmacokinetics of sparfloxacin in healthy volunteers and patients: a review. J Antimicrob Chemother 37: 2739.

4. Schentag JJ (2000) Sparfloxacin: a review. Clin Ther 22: 372-387.

5. Shimada J, Nogita T, Ishibashi Y (1993) Clinical Pharmacokinetics of Sparfloxacin. Clin Pharrnacokinet 25: 358-369.

6. Troeltzsch M, Pache C, Probst FA, Troeltzsch M, Ehrenfeld M, et al. (2014) Antibiotic concentrations in saliva: a systematic review of the literature, with clinical implications for the treatment of sialadenitis. J Oral Maxillofac Surg 72: 67-75.

7. Kiang TK, Ensom MH (2016) A Qualitative Review on the Pharmacokinetics of Antibiotics in Saliva: Implications on Clinical Pharmacokinetic Monitoring in Humans. Clin Pharmacokinet 55: 313-358.

8. Zhanel GG, Walkty A, Vercaigne L, Karlowsky JA, Embil J, et al. (1999) The new fluoroquinolones: A critical review. Can J Infect Dis 10: 207238.

9. Zix JA, Geerdes-Fenge HF, Rau M, Vöckler J, Borner K, et al. (1997) Pharmacokinetics of sparfloxacin and interaction with cisapride and sucralfate. Antimicrob Agents Chemother 41:1668-1672.

10. Johnson JH, Cooper MA, Andrews JM, Wise R (1992) Pharmacokinetics and inflammatory fluid penetration of sparfloxacin. Antimicrob. Agents Chemother 36: 2444-2446.

11. Stass H, Dalhoff A, Kubitza D, Schühly U (1998) Pharmacokinetics, safety, and tolerability of ascending single doses of moxifloxacin, a new 8-methoxy quinolone, administered to healthy subjects. Antimicrob Agents Chemother 42: 2060-2065. 